\title{
Horácio e o uso poético-político do passado
} Horace and his Poetical and Political Uses of the Past

\author{
Camilla Ferreira Paulino da Silva* \\ Leni Ribeiro Leite ${ }^{* *}$
}

\section{Resumo}

$\mathrm{O}$ artigo analisa como o poeta Horácio se apropriou da tradição retórico-poética romana e grega de forma a estabelecer sua posição frente à sociedade romana, no contexto de alargamento de fronteiras e de fabricação de um novo regime político, o Principado de Augusto. O passado, sempre atualizado de acordo com as circunstâncias, é redefinido por Horácio na defesa de seu status, utilizando a sua vitoriosa carreira como um cursus poetarum em espelhamento ao cursus honorum, o que lhe conferia autoridade para proferir conselhos à elite imperial nascente bem como se dirigir a figuras poderosas. Ao longo do século I a.C., muitos novi homines, como Cícero e o próprio Horácio, ascenderam socialmente, sobretudo por sua atuação política e econômica. Como tais homens não possuíam um passado louvável no qual poderiam se apoiar para se estabelecerem política e socialmente, empregaram estratégias retóricas para reescreverem o passado, utilizando-o como ferramenta para se fortalecerem no jogo do poder.

Palavras-chave: Horácio; homo novus; usos do passado.

\begin{abstract}
In this paper, we analyze how Horace, the Roman poet, took on the Greek and Roman rhetorical and poetical traditions in order to establish his own social role, within a context of widening of boundaries and fabrication of a new political regime, the Augustan Principate. The past, always updated according to circumstances, is redefined by Horace in defense of his status, by using his successful career as his cursus poetarum, mirroring the cursus honorum, to confer him authority to advise the newborn imperial elite, as well as converse with powerful figures. Throughout the first century BC, many novi homines, such as Cicero and Horace himself, socially ascended, mainly due to their political and economic performance. As these men did not have a laudable past on which they could rely to establish themselves socially and politically, they employed rhetorical strategies to rewrite the past, using it as a tool to strengthen their own sides in the game of power.
\end{abstract}

Keywords: Horace; homus novo; uses of the past.

\footnotetext{
* Governo do Estado do Espírito Santo, Vitória, ES, Brasil. camillapaulino@gmail.com <https:// orcid.org/0000-0001-9715-8258>

** Universidade Federal do Espírito Santo (Ufes), Vitória, ES, Brasil. leni.ribeiro@gmail.com <https:// orcid.org/0000-0001-6600-7692>
} 
A História Antiga, nas últimas décadas, tem (talvez, finalmente) se dedicado não só aos documentos e monumentos a nós legados pela Antiguidade, mas também às construções desse passado realizadas pelos muitos presentes que sobre ele se debruçaram ao longo do tempo. ${ }^{1}$ Se, como demonstra Silva (2007, p. 99), "Na atualidade, a utilização da História do mundo antigo como instrumento legitimador do ideário de grupos políticos [...] é algo recorrente”, as estratégias de construção discursiva de um passado legitimador ora desta ora daquela realidade presente que se deseja podem parecer uma tática dos modernos, surgida a partir de algum ponto mais recente na cronologia que nos separa da Grécia e da Roma clássicas. No entanto, como pretendemos enfatizar e exemplificar neste artigo, desde a própria Antiguidade o passado é um dispositivo do qual muitos podem se apropriar para justificar determinadas posições e atos seus contemporâneos, e legitimá-los. Nesse procedimento, como demonstra Martins (2011, p. 152), há uma revisitação e uma fabricação do passado e de seus índices linguísticos, tais como tradição, cânone e, para os romanos, mos maiorum.

Mos maiorum, o costume dos ancestrais, foi usado por vários romanos ao se apresentarem como os verdadeiros seguidores de tais costumes, mas é evidente em qualquer exame um pouco mais cuidadoso que não há apenas um mos maiorum: ele é algo reinventado a cada geração, de acordo com as necessidades político-sociais de cada contexto. Não é ele uma tradição ou uma maneira estática de se fazer algo, mas uma estratégia discursiva, dinâmica, forjada para o apelo ao páthos da audiência. Para os aristocratas, posicionar-se como mantenedor do discurso de zelo pelos costumes e afirmar que estavam atuando socialmente em defesa desses costumes era algo muito valioso, e eles valiam-se, nesse esforço, de atualizar e ditar o que seria essa tradição a cada uso do conceito.

Desse modo, vários romanos reivindicaram o fato de serem seguidores fiéis do mos maiorum, de serem adeptos da cultura dos antepassados, uma vez que isso era socialmente muito bem visto e esperado, pois nele se baseava a própria forma como os romanos eram educados (Atkins, 2000, p. 481-482). Assim, com o desenvolvimento da literatura latina, o mos maiorum se torna também um topos recorrente. Por exemplo, Ênio (Ann, 5. 156), citado por Cícero (Rep. 5.1), afirma que "moribus antiquis res stat Romana virisque", "A República romana se mantém pelos seus homens e costumes antigos". ${ }^{2}$ Cícero (Rep. 5.1) retoma essa sentença para corroborar a sua argumentação de que sem os heróis e as instituições do passado não haveria para os cidadãos exemplos inspiradores e condutores à manutenção da República. Na abertura das 
Tusculanas (1.1-2), Cícero (2005) se orgulha do fato de os romanos se mostrarem mais sábios na filosofia quando comparados aos gregos, por preservarem com maior cuidado os costumes e as regras da vida e, em relação à administração pública, por terem herdado dos antepassados as melhores leis e instituições. Ao fazer essa declaração, Cícero, evidentemente, elogia não só os romanos, mas a si mesmo, utilizando o recurso do passado glorioso comunitário, não exclusivo de uma família ou de um indivíduo. Já Horácio, no Carm. 2.15 (10-12), ${ }^{3}$ emulando o topos da exaltação à vida simples, condena o luxo em que viviam os seus contemporâneos, justificando que "não foi isto que Rômulo, o severo Catão e as normas dos antigos nos prescreveram" ${ }^{4} \mathrm{Na}$ última das chamadas "Odes Romanas", assim chamadas por seu teor cívico, Horácio faz mais uma vez um lamento pelos tempos imorais em que vive, pontuando que já houve uma época em que os romanos eram gloriosos, quando, no passado, ancestrais honrados derrotaram inimigos externos poderosos (Hor. Carm. 1.6, v. 33-44). O passado aparece e é construído como um recurso retórico-poético utilizado para vituperar práticas consideradas ruins pelo enunciador do poema.

No decorrer do século I a.C. existiam pelo menos duas razões para que os mores maiorum estivessem presentes com alguma frequência no discurso aristocrático, sendo a primeira delas o fato de que abstratamente se estabeleciam as regras de funcionamento da coisa pública entre a elite com base nos costumes, e a segunda, o fato de que o mos maiorum poderia servir como um tipo de barreira a ser superada pelos novi homines ${ }^{5}$ provenientes das províncias romanas e que estavam cada vez mais ingressando nos espaços anteriormente restritos a um círculo de pessoas em Roma. Como o passado é a chave para que algo seja tido como tradicional e esses novi homines não podiam contar com isso para legitimar sua ação e prestígio, o discurso da salvação dos costumes funcionava como uma importante estratégia retórica para as elites.

Por isso ocorreu uma disputa em torno da definição do que deveria ser considerado mais importante para que alguém alcançasse os mais altos cargos da vida pública romana, parecendo haver cada vez mais um deslocamento da definição do status de elite política, em que não mais sobressairiam o nascimento e a família, mas sim os méritos e as realizações dos indivíduos (Flower, 2006, p. 325). Argumentamos que uma expressão desse deslocamento pode ser vista na produção poética contemporânea de Horácio, na performance poética que se desenrola em cada uma de suas produções, a saber, os dois livros de Sátiras (Sermones), publicados entre 35 e 30 a.C.; um livro de Epodos (Epodon liber, 30 a.C.); três livros de Odes (Carmina), publicados por volta de 23 a.C.; o primeiro livro de Epístolas (Epistulae) em 20 a.C.; seguido do Carme Secular 
(Carmen Saeculare), em 17 a.C.; do segundo livro de Epístolas (Epistulae) e do quarto e último livro de Odes (Carmina), entre 11 e 8 a.C., data da morte do poeta. Esse conjunto de poemas, se lidos paralelamente por meio dos expedientes poético-retóricos caros à época e dos elementos culturais e políticos contemporâneos, constitui uma proposta audaciosa de transfiguração do cursus honorum tradicional aristocrático em um cursus poetarum, que desestabiliza as definições de libertas, dignitas, auctoritas e outras pedras angulares do cidadão romano, refundindo-as e recriando-as em novos usos de um passado tradicional romano, sedimentado a serviço de uma cidade de influência local e governo republicano, para a sede de um império global sob a égide de um imperador.

\section{Metamorfoses ACELERADAS: O SÉCUlo I A.C.}

É de alguma forma natural, ou ao menos mais esperado, que em momentos de rápida mudança política as revisões dos usos do passado se deem de forma mais aguda. A elite romana passou por profundas mudanças no século I a.C. Inicialmente, entre 91-88 a.C., essa mudança de paradigma ocorreu em meio à Guerra Social, na qual Roma pelejou contra os socii itálicos. Nesse conflito não só pereceu um número grande de homens - dentre os quais romanos dos estamentos mais altos - como também ocorreu a ampliação do número de cidadãos, graças a uma série de leis aprovadas como meio de cessar o confronto, atendendo às demandas feitas pelas elites provinciais da península itálica (Steel, 2013, p. 80-85). O impacto da expansão da cidadania foi marcante, pois assinalou a reorganização da gestão da res publica, movimento sentido principalmente a partir da década de 70 a.C., quando os municipia passaram a ser inscritos nas votações ${ }^{6}$ e as elites provinciais puderam não só competir por cargos locais, mas também se lançar aos mais altos postos da vida pública em Roma (Patterson, 2006, p. 614).

Essa modificação nas estruturas políticas e sociais causou agitação entre as elites tradicionais romanas, que passaram a ver os provinciais cada vez mais fortalecidos, disputando o que antes era o seu campo exclusivo de poder. Isso porque, como apresenta Morley (2006, p. 308), no século I a.C., a ideia de cidadania em Roma passou por muitas transformações para além da sua ampliação para toda a península itálica, como a extinção do imposto sobre propriedade e a gradação do serviço militar de acordo com a riqueza. Esses episódios, ainda segundo Morley (2006, p. 308-309), demonstram que o modelo de cidade-Estado foi abandonado e, de um grupo pequeno porém consistente de 
cidadãos, Roma passou a ter o seu corpo social composto por pessoas de amplas e diferentes proveniências, identificadas tanto com sua origem local, quanto com a Vrbs, num processo de modificação de uma estrutura local para uma estrutura global.

Um indicativo dessa mudança realiza-se com Sula, um dos líderes romanos de destaque na Guerra Social, que após o encerramento do conflito aprovou a reformulação do Senado, aceitando, a partir de então, equites em suas fileiras, incluindo aqueles provenientes das províncias que lhe tivessem sido apoiadores. ${ }^{7}$ Santangelo (2006, p. 14) argumenta não haver evidências de que Sula tenha dobrado o número de senadores, tal como defendido por alguns pesquisadores, como David (2006), Konrad (2006), Gelzer (1912) e Gabba (1976); sabe-se, porém, que ele permitiu que certo número de pessoas de baixo status entrassem no Senado, o que lhe rendeu uma série de críticas, porque a nobilitas tradicional, ${ }^{8}$ patrícia, empenhava-se em manter a sua exclusividade entre os membros do Senado e os que ascendiam ao consulado, com base no discurso de ser este sua prerrogativa, salvaguardada por seu nascimento e por sua tradição (Syme, 2011, p. 22-23). Sula, porém, defendia a causa desses aristocratas tradicionais, conforme se pode interpretar por suas medidas e também pelo modo como Cícero (Rosc. Am. 135; 38) se referiu a ele, enunciando expressamente que o general era pró causa nobilitatis.

Outro exemplo de mudança e tensão está em Salústio (Iug. 63), que narra a dificuldade de alguém como Mário em obter o consulado, ${ }^{9}$ embora fosse qualificado em vários aspectos, simplesmente porque ele era um nouus homo, um homem novo, e os aristocratas consideravam uma desonra que alguém de fora de seus círculos alcançasse tal magistratura: "Nenhum homem novo era tão distinto ou importante nos feitos que não fosse julgado indigno daquela honra [consulado] e tido como sujo". ${ }^{10}$ No Commentariolum petitionis, no qual Quinto Túlio Cícero aconselha o irmão Marco Túlio Cícero sobre a forma correta de se portar para obter o consulado, fica expresso que para que um nouus homo fosse vitorioso na obtenção de tal cargo era necessário convencer os aristocratas de que o candidato possuía os mesmos interesses, não partilhando as demandas do grupo que ficou conhecido como populares, cuja pauta ia de encontro ao patriciado tradicional. ${ }^{11}$ Esse aconselhamento fundamentava-se no fato de que a elite tradicional parecia estar procurando resguardar a sua preeminência de todas as formas possíveis. Cícero (Leg. Agr. 2.3), por exemplo, de modo a valorizar o seu ingresso no consulado, acentua ter sido o primeiro homo nouus eleito após um amplo período, enfatizando que a magistratura constituía uma posição "a qual a nobilitas havia mantido em segurança e cercado com todo cuidado", deixando 
entrever que, nos anos em que pôde, a elite tradicional buscou eleger cônsules somente entre eles próprios.

É nesse cenário que Horácio irrompe, ele mesmo um cidadão romano de origem obscura, como menciona ao se descrever como "libertino patre natum", "nascido de pai liberto" (Hor. Sat. 1.6.6). ${ }^{12}$ Parte da ordem equestre, Horácio legou-nos uma série de obras em verso que coincidem temporalmente com a ascensão de Otávio à cabeça do Império e, como procuraremos demonstrar, desenvolvem coetaneamente as imagens do poeta e do cidadão romano, e sua performance literária torna-se ao mesmo tempo uma performance social de apreensão das unidades codificadas da tradição e do passado romanos e sua recodificação para uma nova realidade política.

\section{HorÁCIO, HOMO NOVUS, POETA SOCIAL}

Antes dos poetas latinos, segundo Farrell (2002), não há evidência de que os artistas da Grécia clássica ou helenística moldassem suas experiências como se progredissem em uma carreira, tal como acontece em Roma, principalmente a partir do século I a.C. Herdeiros diretos do refinamento e da erudição dos poetas de Alexandria e Pérgamo, em Roma os poetas estavam em posição social muito diversa da dos poetas gregos em geral, os quais eram vistos por suas comunidades como membros respeitados. Os primeiros poetas latinos, ao contrário, chegam ao Lácio como presa de guerra, e desde o começo a produção literária foi integrada às dinâmicas sociais, com os poetas ligados aos patronos romanos. Estes, vivendo num mundo extremamente competitivo, precisavam o tempo todo se reafirmar publicamente para obter e assegurar uma carreira bem-sucedida, a qual se expressava com a progressão nos cargos da sequência do cursus honorum. Imersos nessa cultura aristocrática, "não é surpresa encontrar os poetas gradualmente desenhando para eles próprios carreiras modeladas conforme a de seus patronos aristocratas" (Farrell, 2002, p. 35).

Analisando a carreira de Lívio Andrônico, por exemplo, Farrell (2002, p. 36) mostra como esse poeta, em 207 a.C., durante o segundo consulado de seu patrono Marco Salinator, produziu um hino para ser cantado publicamente por um coro de meninas, num momento crítico das Guerras Púnicas, o qual, tendo alcançado grande sucesso, propiciou ao poeta uma série de honras públicas. O seu êxito, segundo argumenta Farrell, resultou do fato de que um cônsul o patrocinava, e o valor de sua poesia era, pois, avaliado pelo serviço prestado à res publica. Como os primeiros passos do cursus honorum dos aristocratas previam que eles promovessem uma série de entretenimentos para o 
populus, os quais podiam ser performances esportivas mas também artísticas, desde o século III a.C. há uma interdependência entre poetas e políticos.

Na passagem para o século I a.C., alguns aristocratas começaram eles mesmos a se aventurar na escrita de poesia, embora fosse ainda algo tomado como passatempo, não como uma verdadeira carreira, até Catulo, pelo menos. Afinal, o sucesso em Roma media-se pelas vitórias na vida política, militar, ou nas disputas judiciais, e a erudição, embora fosse bem-vista, era primordialmente reservada para os momentos de otium, preferencialmente quando servisse para aumentar a habilidade do indivíduo em sua busca pelo sucesso na vida pública (Rawson, 1985, p. 38). Cícero (De or. 1.1), porém, faz a célebre associação “in otium cum dignitate", relacionando otium, ou seja, o tempo livre das obrigações, com a dignitas, ${ }^{13}$ o valor, o prestígio adquirido por um romano ao longo de seu cursus honorum. Vale pontuar, ainda, que nessa passagem o orador está vinculando esse otium cum dignitate aos antepassados, os que viveram no apogeu da República, que se mantinham honrados tanto ao exercerem alguma função pública quanto ao se afastarem dela. Esse valor aristocrático é apropriado por Horácio em sua Epístola 1.2, em que o poeta se representa relendo Homero quando está afastado de Roma, ou seja, do centro do poder, de onde as coisas públicas são geridas. Em seu otium, o poeta extrai da leitura da Ilíada e da Odisseia uma série de bons conselhos e exemplos, mostrando, por espelhamento (porque o próprio discurso de Horácio é um poema), a relevância de ler e fazer poesia, uma forma de exaltar seu próprio cursus poetarum.

De toda forma, nesse período uma gradual mudança começa a acontecer, e Lucílio é uma referência nesse sentido. Ele é o primeiro membro da aristocracia a contribuir tal como um poeta profissional para a literatura latina, sendo visto como o criador do gênero satírico; ao investir boa parte de seu tempo ao fazer poético, Lucílio estava lançando bases para que a carreira poética fosse vista de uma perspectiva independente, desvinculada de patronos, como uma possível via de ocupação para homens de posição social distinta (Farrell, 2002, p. 41-42). Essa concepção é aprofundada por Catulo, também procedente da aristocracia, o qual fala com descontentamento sobre o cursus honorum tradicional (cf. Catulo 10 e 28), ${ }^{14}$ manifestando a ideia de que uma vida dedicada à poesia poderia ser "uma carreira suficientemente desafiadora e recompensadora para um membro da ordem governante" (Farrell, 2002, p. 43). Lucílio e Catulo, embora fossem exceções em seus tempos, são importantes precedentes para os poetas da geração augustana, fornecendo capital simbólico (Bourdieu, 2009, p. 145) para que poetas como Horácio pudessem reivindicar a carreira poética como legítima alternativa ao cursus honorum 
tradicional. Ao selecionar Lucílio como seu principal modelo nas Sátiras, Horácio está não só fazendo uma emulação literária, mas também demarcando que, assim como esse antepassado poético, ele também escolhera vivenciar poesia como carreira; sendo Lucílio um reconhecido poeta, funciona como capital simbólico para a legitimação de Horácio.

Harrison (2010) analisa a trajetória poética de Horácio percebendo como ele caminha pelos gêneros literários de forma ascendente até a publicação das Odes, em 23 a.C., partindo do sermo humilde e apolítico para uma poesia lírica engajada. Após essa data, Horácio passa a trabalhar sermones e poesia lírica de modo alternado. Harrison (2010, p. 40), então, aventa a possibilidade de captar Horácio construindo um paralelo entre a sua carreira poética e a carreira política tradicional, e para isso traz como evidência o modo como Horácio, no Carmen 1.1, ao apresentar uma série de escolhas de vida ao longo do poema, rejeita todas as opções em prol da carreira poética. O autor mostra que há um contraste entre os versos 7-8, em que o político se esforça nas eleições ("hunc, se mobilium turba Quiritium/ certat tergeminis tollere honoribus", "este gosta de ver tantos romanos em vão/ combaterem para levar as honras trigêmeas"), e os versos finais, em que Horácio apresenta a sua inserção entre os poetas como fruto de um chamado divino ("Me doctarum hederae praemia frontium/ dis miscent superis [...]", "Quanto a mim, uma hera, ${ }^{15}$ honra dos homens cultos,/ junto aos deuses me uniu; [...]”, v. 29-30). ${ }^{16}$

A primazia de sua vida de poeta em detrimento das atividades tradicionais da Vrbs é uma imagem trabalhada por Horácio desde as Sátiras, suas primeiras publicações. Na Sátira 1.6 (v. 110-126), por exemplo, Horácio representa a sua vida como melhor que a de um senador, ou seja, melhor que a de um indivíduo da primeira ordem romana:

Por isso, e por mil outras razões, vivo mais comodamente que tu, ilustre senador. Vou sozinho para onde me dá vontade, pergunto o preço dos legumes e do trigo, frequentemente passeio ao anoitecer pelo circo embusteiro e pela praça [...] vou dormir despreocupado, porque amanhã não tenho de me levantar cedo [...]. Fico deitado até as dez horas, depois passeio e, tendo lido ou escrito em silêncio, o que me agradar, unto-me com óleo perfumado [...]. Mas quando o sol mais ardente aconselha a mim, cansado, a ir banhar-me, fujo da canícula ardente. (grifo nosso) ${ }^{17}$

Nesse trecho, chamado de "diário de um ninguém" por Gowers (2003, p. 80), Horácio mostra que sua escolha em trilhar uma vida longe da ambição política lhe proporcionou uma rotina despreocupada e digna de ser vivida. 
Horácio se movimenta nesse tema desde o início dessa sátira, que, como aponta Oliensis (1998, p. 30), embora direcionada a Mecenas, é designada também para responder aos que porventura pudessem acusar Horácio de ser um indivíduo ganancioso. Como se abstém da atribulada vida dos scurrae, que têm sempre de estar atrás de pessoas importantes para prestar e pagar favores, ele é livre e pode desfrutar de uma rotina calma, sem ter de se submeter a pessoas e eventos que pudessem ferir a sua dignidade (Oliensis, 1998, p. 34-35). Essa valorização da vida simples é retratada pela apropriação de um preceito epicurista, retomado mais tarde na Epístola 1.18 (v. 10), quando Horácio diz que "nec uixit male, qui natus moriensque fefellit", "nem viveu mal quem ao nascer e morrer passou despercebido".

Um dado que nos chama a atenção no contraste criado por Horácio, nessa sátira, entre a sua vida não atribulada e a vida pública, é a quantidade de vezes que o poeta cita magistraturas romanas e, no contexto, faz algum tipo de paralelo com a sua condição de "nascido de pai liberto", libertino patre natum (v. 6). Em outras sete passagens da sátira ele menciona seu nascimento obscuro (v. $21,29,36,45,46,58,64$ ), e em duas ocasiões o poeta repete exatamente as mesmas palavras do verso 6 . A nosso ver, essa repetição cumpre um expediente dentro da sátira, o de gerar um efeito cômico, mas não podemos esquecer que o riso, conforme Miotti (2010, p. 212-213), tornando leve determinadas lições, poderia ser um facilitador da transmissão de ensinamentos e mensagens. Woodman (2009, p. 158) propõe que o poeta estivesse buscando outra associação por meio dessa ênfase, a saber, com Cneu Flávio, edil em 304 a.C., o qual foi descrito tanto por Valério Máximo (2.5.2) como por Plínio, o Velho $(\mathrm{NH}, 33$, 17) e por Tito Lívio (9.46.1) justamente como "nascido de pai liberto". Esses autores citados são posteriores a Horácio, mas há um fragmento de Calpúrnio Piso, historiador e cônsul em 133 a.C., que também descreve Flávio justamente como patre libertino natus, "nascido de pai liberto" (Woodman, 2009, p. 159). Cneu Flávio parece ter sido um modelo exemplar para aqueles indivíduos de semelhante condição social, e, assim, é possível que por meio da repetição do termo libertino patre natum Horácio estivesse convidando os seus contemporâneos a estabelecer uma relação entre o poeta e esse edil, uma figura importante da tradição que, assim como Horácio, era filho de liberto e atuara como escriba. E, assim como Horácio constrói ao longo dessa sátira a imagem de que sofria com críticas em razão de seu baixo nascimento, também Cneu Flávio, no fragmento de Piso citado por Woodman (2009, p. 159), foi desprezado por jovens nobres que não aceitavam alguém fora da nobilitas tendo alcançado a honra de se tornar edil. A figura de Cneu Flávio é já um exemplo de como 
Horácio toma figuras do passado e modifica sua atribuição de valor, usando-os como elementos positivos, quando em seu contexto de origem eles poderiam ser vistos como negativos.

A oficialidade romana aparece também contrastada com a condição de libertino patre natus nos versos 19-21, em que o poeta menciona a censura e o Senado; nos versos 25-29, novamente o Senado e o tribunato; e nos versos 4548, com o tribunato militar. ${ }^{18}$ Nos versos 96-99, Horácio argumenta que se fosse possível nascer de novo, não optaria por nascer em outra família: "contente com os meus, eu não quereria tomar para mim aqueles honrados com os feixes de varas e a cadeira curul. Segundo o julgamento do povo, eu seria louco; talvez sábio, no teu [Mecenas], porque eu não queria carregar um peso incômodo a que não estava acostumado" ${ }^{19}$

Tanto os fasces como a cadeira curul, distintivos que marcavam a autoridade dos políticos, são negados por Horácio, e os cargos públicos não são representados como uma honra, mas como um onus, um fardo (v. 99). O poeta conta ainda, em sua construção poética, com a importante aprovação de Mecenas, como atesta o trecho citado. Vale lembrar que esse patrono, diretamente envolvido com assuntos políticos por meio de sua associação com Otávio, optou por permanecer um privatus equestre, ainda que pudesse ter ingressado, se quisesse, na ordem senatorial e alcançado as mais altas magistraturas. Há, aqui, um espelhamento entre esse romano poderoso e o poeta, auxiliando Horácio a defender que a sua vida afastada das coisas públicas também era uma opção digna, a qual Mecenas não só aprova mas também vivencia (DuQuesnay, 2009, p. 89; 91-92). ${ }^{20}$

Nos versos finais da sátira (128-131), após demonstrar o quão boa era a sua vida longe das atribulações de quem perseguia o cursus honorum, Horácio faz a seguinte peroratio: "Essa é a vida dos homens livres da mísera e prejudicial ambição; com essas coisas eu me convenço de que viverei mais agradavelmente do que se meu avô, meu pai e meu tio tivessem sido questores" ${ }^{21}$ Como aponta Oliensis (1998, p. 31), a ambição criticada por Horácio aqui é a daqueles que perseguiam interesses políticos, algo fora de cogitação para o poeta que se representa aliviado por não pertencer a uma família com passado político, o que consequentemente o impeliria a seguir o mesmo cursus de seus parentes. DuQuesnay (2009, p. 90) afirma que nesses versos finais Horácio está desafiando os valores tradicionais romanos ao defender a ideia de que uma vida de otium, longe da gestão da res publica, pode não só perfeitamente satisfazer o ideal romano de libertas, ${ }^{22}$ mas também ser superior à busca pela glória. A glória, valor fundamental entre os aristocratas, que competiam por ela em meio 
às disputas públicas, é mencionada nos versos 23-24 como um algo negativo e perigoso, e aqueles que a buscavam são representados como presas de guerra (DuQuesnay, 2009, p. 86). Aqui, aliás, o exemplo de Mecenas é, mais uma vez, de suma importância, pois ele representa um novo modo de contribuir para a res publica: ele não participa do jogo político procurando disputar glória e cargos elevados, mas como um leal privatus que apoia um amigo, o que no caso dele significava amparar Otávio sempre que este lhe solicitasse (DuQuesnay, 2009, p. 92).

\section{O CURSUS POETARUM COMO CONTRAPARTE DO CURSUS HONORUM}

Harrison (2010, p. 39) também afirma que a carreira poética de Horácio é construída como forma de dar prosseguimento à sua carreira pública. $\mathrm{O}$ poeta havia exercido, antes de começar a publicar seus primeiros poemas, o posto de tribuno militar. Esse posto era um dos cargos que os romanos membros da nobilitas tradicionalmente exerciam como primeiro passo no cursus honorum, precedendo a questura (Abbott, 1901, p. 168). Horácio (Sat. 1.6, v. 50) afirma que muitos o invejaram por ele ter exercido tal posto sob o comando de Bruto, mas de tribunus militum Horácio não segue para outros cargos militares, e sim passa a ser poeta, iniciando em gêneros mais humildes até se transformar no vate ${ }^{23}$ laureado do Carmen Saeculare; essa ascensão diz respeito, claro, aos gêneros literários, mas concordamos com Harrison (2010, p. 40) em que ela pode e deve ser relacionada com a ascensão político-social do poeta.

Harrison (2010, p. 41-42) demonstra como no primeiro livro das Sátiras há uma espécie de progressão autobiográfica, iniciada com o poeta se caracterizando como um moralista excluído, um pregador urbano isolado que, a partir da Sátira 1.4, começa a se integrar ao círculo de Mecenas, culminando no último poema, Sátira 1.10, com Horácio completamente familiarizado e inserido entre os amigos do patrono, os escritores mais renomados da época. Nos versos 81-92 Horácio argumenta que escreveu seu livro de sátiras esperando a avaliação e aprovação desses poetas (bem como dos patronos Messala, Polião e Mecenas). O apelo aos críticos no final da obra, segundo demonstra Harrison (2010, p. 43), era "um gesto padrão da poesia latina do período triunviral, e um modo padrão de marcar a entrada de um novo trabalho, e, no caso de Horácio, de um novo poeta, cuja carreira literária é agora lançada sob auspícios impressionantes". Carreira poética e avanço social estão, assim, imbricados. Se no primeiro livro de Sátiras, por exemplo, Otávio só é mencionado por intermédio de Mecenas, no segundo livro, publicado 5 anos depois, Horácio 
já alcança uma elevação social que lhe permite dirigir-se diretamente ao filho de César no primeiro poema, bem como louvá-lo diretamente na Sátira 2.5, sem recorrer a Mecenas (Harrison, 2010, p. 44).

Depois das Sátiras seguiram-se os Carmina, as Odes, muitas das quais têm caráter político e cívico claro e bem definido, tais como a famosa Ode iniciada com Nunc est Bibendum (Carmen 1.37), que abertamente comemora a vitória de Otávio sobre Cleópatra e Marco Antônio. Há, no entanto, já nas Odes um deslocamento da ênfase, da vida pública e política para a vida privada, conforme o poeta vai envelhecendo no ofício, e fazendo jus, como um soldado, à sua aposentadoria. Syme (1986, p. 386) argutamente observa que, nos próprios Carmina, progressivamente o poeta vai diminuindo a menção a personagens aristocratas, fortemente presentes nos três primeiros livros, até praticamente desaparecerem no último: esse movimento expressava também o panorama político, já que, na época de publicação do quarto livro de Carmina, em 13 a.C., a posição de Augusto e sua domus na política romana estava bem cimentada.

No poema que encerra os seus primeiros livros de Odes, o Carmen 3.30, Horácio lança mão do topos da perenidade para mostrar que a sua poesia duraria por toda a eternidade e, dessa forma, como analisa Martins (2011, p. 137-138), tanto as pessoas figuradas na coleção quanto o próprio poeta durariam para sempre, sobrevivendo à própria morte ("non omnis moriar multaque pars mei/ uitabit Libitinam", "não morrerei completamente, e muita parte de mim sobreviverá à Libitina”, v. 6-7). Dialogando com esse poema e subvertendo esse anseio pela eternidade da coleção de odes, na sphragis ${ }^{24}$ da Epístola 1.20 o poeta, de modo jocoso, agora apresenta pretensões bem menores, profetizando, nos versos 11-13, que o seu livro será esquecido e comido pela traça, após ser manuseado por um tempo pelo povo, o vulgus de que tanto Horácio buscara se afastar na poesia anterior (Harrison, 1988, p. 473-474).

Esse esvaziamento de sentido é, claro, expressão do fato de que seus sermones não podem clamar pelos resultados grandiosos da poesia lírica. Sendo as Epístolas poemas-cartas, e as cartas registros datados, Horácio, nos últimos versos, faz menção ao tempo, registrando a sua idade e quem eram os cônsules daquele ano (21 a.C.): "me quater undenos sciat impleuisse Decembris/ collegam Lepidum quo duxit Lollius anno", "saiba que completei quatro vezes onze dezembros/ no ano em que Lólio trouxe Lépido como colega” (v. 27-28). Essa era a forma como os romanos se referiam aos anos nos seus livros de história, "sugerindo, talvez, que o primeiro livro de Epístolas seja um tipo de crônica cômica de sua vida em Roma” (Harrison, 2007, p. 31). Trazer o livro para a realidade temporal romana é uma forma de reafirmar o seu caráter transitório 
e humano, opondo-se ao modo como ele se apresenta na coleção lírica, que transcende o tempo e o espaço (Harrison, 1988, p. 475).

A idade que Horácio registra ao final da coleção não é, contudo, um registro fiel, por assim dizer, já que as Epístolas vieram a público um ou dois anos após o poeta ter essa idade; o registro não é, pois, para atestar a idade exata da publicação do livro, mas sim para criar um contraste entre a idade de Horácio e a idade tradicional em que os romanos alcançavam o ápice do cursus honorum, obtendo o consulado por volta dos 42 anos (Harrison, 2010, p. 51-52). Com 44 anos, Horácio pode se retirar da vida pública, tal como ele se representa na cenografia epistolar, expressa tanto pelo abandono da lírica, na Epístola 1.1, quanto pelo afastamento da Vrbs e retirada para o campo. Mas, como atesta no poema anterior (Epistola 1.19), como poeta ele havia integrado o ambiente público, elevando a dicção para compor poemas, por exemplo, como os que abrem o livro 3 dos Carmina, em que pode se nomear até mesmo $\mathrm{Mu}$ sarum sacerdos, sacerdote das musas (Carm. 3.1, v. 3). Como em Roma o campo político e o sagrado se imiscuíam, a escolha do poeta em representar-se como um sacerdote justamente na abertura de seus poemas políticos, quando contava com a idade consular, é no mínimo curiosa. Os cônsules, além de suas funções financeiras, jurídicas e políticas, tinham também deveres sacerdotais, como o de tomar auspícios antes da eleição de um magistrado, da reunião dos comitia ou do início de uma campanha militar, o de fazer sacrifícios e dedicar templos (Abbott, 1901, p. 177). Há um entrecruzamento sofisticadamente criado por Horácio entre o poeta, o político e o sacerdote, que serve para justificar e ampliar a sua imagem.

As Odes funcionam como o ápice do que podemos chamar, em comparação com o cursus honorum romano, seu cursus poetarum até aquele momento, quando Horácio executou um papel cívico importantíssimo, o de bardo que fala para o povo romano, elogiado e lido pelos principais cidadãos; a memória dessa performance funciona como base da sua auctoritas como cidadão romano, ${ }^{25}$ tal como o consulado seria para um político romano mais velho; seu desempenho lírico o ratifica como um auctor que intervém na sua sociedade, voltando-se então já nas Epístolas para o aconselhamento dos membros mais jovens. Investido de um éthos filosófico, o autor busca orientar outros indivíduos, todos pertencentes a uma elite romana em transformação e não necessariamente pertencentes à nobilitas tradicional. Incorporando uma figura professoral, que, como um pai, ensina ao filho como fugir dos vícios mostrando vários bons e maus exemplos, Horácio ao falar de si em primeira pessoa nas Epístolas posiciona-se como exemplum a ser imitado, convergindo ficção e realidade, pois 
não só seus feitos no campo da literatura serão empregados para reforçar a sua imagem, mas também a sua bem-sucedida ascensão social e o equilíbrio no relacionamento com poderosos serão um exemplo real a ser seguido.

É significativo o fato de que Horácio escolheu direcionar a maioria desses poemas a jovens que, embora pertencessem à aristocracia, eram tal como o poeta recém-chegados, possivelmente equestres que também estavam associando-se a pessoas eminentes em busca de um cursus honorum bem-sucedido (Mayer, 1994, p. 7). Esses novos aristocratas compõem a corte nascente do princeps e por isso deveriam saber como se portar frente a este e sua família, evitando a falta de decorum. Lólio, que recebe duas epístolas significativas tanto por seu conteúdo quanto pela posição de prestígio no livro (Epist. 1.2 e 1.18), era um homo nouus, parente de Marco Lólio, cônsul em 21 a.C., e, como Mayer (1994, p. 9) ressalta, não tinha uma ancestralidade para lhe dar suporte, o que o tornava um ótimo destinatário para uma epístola em que as armadilhas do patronato são expostas.

O valor concedido por Horácio ao cursus poetarum em comparação à carreira tradicional fica atestado ainda por duas passagens da Epístola 1.3. Nela, o poeta busca saber notícias de vários amigos, os quais possivelmente eram também próximos a Tibério, tal como é o caso de Celso, citado no verso 15, e que aparece novamente na Epistola 1.8 descrito como "comiti scribaeque Neronis", "companheiro e secretário de Nero" (v. 2) - Tibério era Tibério Cláudio Nero. O poema inicia com Horácio mostrando-se curioso sobre os feitos militares de Tibério ("Iuli Flore, quibus terrarum militet oris/ Claudius Augusti priuignus, scire laboro", "Júlio Floro, em que terras do mundo milita/ Cláudio, enteado de Augusto, inquieto-me para saber", v. 1-2; "Quid studiosa cohors operum struit? hoc quoque curo", "Que obra prepara a empenhada coorte? Isso também me interessa", v. 6), quando, parataticamente, o poeta muda o objeto de curiosidade, passando a perguntar sobre os empreendimentos poéticos: "Quis sibi res gestas Augusti scribere sumit?/ bella quis et paces longum diffundit in aeuum?", "Quem se encarrega de escrever os feitos de Augusto?/ Guerras e pazes, quem as transmite ao longo tempo?" (v. 7-8). A parataxe, aliás, era um recurso característico da poesia épica, de onde advém o metro empregado por Horácio nas Epístolas, e pode ser visto como uma forma de o poeta dialogar com essa tradição (principalmente em um poema no qual mostra-se interessado em matéria guerreira, subsequente à Epístola 1.2, em que Homero é o tópico principal). Ao coordenar as duas sentenças, Horácio está correlacionando os feitos militares com a atividade poética em dois níveis: primeiro, ao mostrar igual curiosidade em saber das duas coisas e, segundo, ao mostrar que 
é necessária a produção de um poeta para que os sucessos bélicos de alguém sejam imortalizados.

Na sequência, Horácio apresenta-se bastante curioso sobre a produção poética de Tício e Celso, e, voltando-se para o destinatário da carta, pergunta:

[...] E tu, o que tentas?

Andas leve ao redor de que flores? Não é pequeno teu

engenho, não é inculto nem torpemente áspero;

quer afies tua língua nos processos, quer te prepares

para responder no direito civil, quer componhas amável verso,

levarás o primeiro prêmio de hera vencedora. (v. 20-25) ${ }^{26}$

Pela descrição de Horácio, Floro era um indivíduo atuante na oratória, no tribunal e na poesia. Ao demonstrar que o amigo poderia ter sucesso em qualquer uma dessas áreas, Horácio acaba, por associação, sugerindo que o valor da dedicação à literatura pode ser equiparado a atividades das instâncias mais formais da vida romana, um caminho legítimo para quem quisesse alcançar o reconhecimento social (O’Neill, 1999, p. 81).

Em suas últimas obras, como a Arte Poética, a Epístola a Augusto e a Epístola a Floro, Horácio parece se caracterizar como um censor. O censor, conforme Abbott (1901, p. 191-192), tinha como encargos organizar os cidadãos em tribos, classes e centúrias, revisar a lista de equestres e senadores, bem como fazer a manutenção do erário público; ao realizar essas tarefas, ele também exercia uma supervisão sobre a moral pública. Utilizando um tom protréptico, o poeta coloca-se no papel daquele que prescreve as regras do que seria a boa e a má poesia, listando quais poetas eram dignos de ser lidos, quem poderia se chamar de poeta, bem como define que tipo de conduta deveriam ter as pessoas empenhadas em seguir o cursus poetarum. Na Arte Poética (v. 306-308), por exemplo, descreve da seguinte forma o conteúdo de seu poema aos Pisões: "munus et officium [...] docebo,/ unde parentur opes, quid alat formetque poetam,/ quid deceat, quid non, quo uirtus, quo ferat error", "ensinarei, [...] o ofício e o dever,/ de onde se obtêm os recursos, o que nutre e modela o poeta,/ o que convém, o que não, para onde leva a virtude, para onde o erro" (Horácio, 2017). Isso ocorre porque, como Oliensis (2009, p. 451) afirma, a imagem projetada por Horácio é a de uma autoridade poética que adquiriu a prerrogativa de instruir, e não só sobre o fazer literário, mas também sobre questões sociais, tendo em vista que essas duas áreas estão indissociadas. 
Como atesta Harrison (2010, p. 56-57), nessas epístolas, como se fizesse uma retrospectiva de sua carreira poética, Horácio enfatiza com mais veemência o seu posicionamento dentro da tradição literária e o valor da poesia para a comunidade romana. Ao lançar um olhar sobre a sua carreira, mostrando a variedade de gêneros em que trabalhou (Epist. 2.2, v. 59-60; Ars P. 79-85), Horácio "apresenta uma imagem consistente do poeta em seus 50 anos, um autoconstruído e laureado romano no final de uma carreira distinta [...]” (Harrison, 2010, p. 58).

Um paralelo ainda mais significativo, porém, é oferecido pelo uso do termo princeps na poesia horaciana. Augusto $(R G 13 ; 30,32)$ é aclamado pelo título republicano princeps senatus, e Horácio mesmo usa tal termo para se referir ao imperador em algumas ocasiões (Carm. 1.2, v. 50; 1.21, v. 13). Princeps era um termo utilizado naquele momento para se referir a um cidadão notável por seus feitos, aquele cuja auctoritas seria excepcional. Dizia respeito não a um cargo oficial, como posteriormente viria a ser, mas a indivíduos que fossem influentes, podendo o termo ser traduzido como "primeiro" ou "principal” (Gruen, 2007, p. 34). Esse é o termo de que Horácio se apropria para falar de si no Carmen 3.30, v. 13, e também na Epístola 1.19:

Livres pegadas por vias vagas deixei, príncipe, alheias não pisei. Quem se fia em si, qual rei, rege o enxame. Eu primeiro os pários iambos ao Lácio dei, [...]

Não me adornes a fronte com folhas menores, porque temi trocar a arte e os modos dos versos: [...]

Esse [Alceu], jamais cantado, eu divulguei, qual lírico latino; alegra-me, cantor de novidades, ser lido e compulsado por olho e mão livres. [...]se eu falo: "Em teatros repletos, por pudor não recito escritos ruins, nem prezo ninharias", um diz: "Ris e aos ouvidos de Júpiter os guardas; fias que exalas da poesia o mel tu só, belo a ti" (Epist. 1.19, v. 21-34; 41-45). ${ }^{27}$

Horácio é um princeps que se vincula aos principes romanos por meio de sua poesia, o que é um motivo de grande honra. ${ }^{28}$ Sua poesia não é para o vulgo (como no Carmen 3.1), mas para os ouvidos de Júpiter, metáfora utilizada que pode tanto se referir aos poderosos em geral, como ao próprio Augusto, porque, 
afinal, dentro do livro é o imperador aquele para quem Horácio envia os seus carmina (cf. Epist. 1.13). Há, aqui, um elogio de mão dupla: Augusto é douto e por isso recebe a poesia de Horácio, que, como produz algo distinto, pode se dirigir ao primus inter pares. Como duvidar da auctoritas de alguém que pode enviar diretamente os seus escritos para a pessoa mais importante de Roma?

Se ao empregar o termo princeps o poeta está emulando o ideal calimaqueano de originalidade poética, ao se representar como "um cantor de novidades", ao mesmo tempo, como Zetzel (1982, p. 96) assevera, ao tomar o título para si o poeta estava se apresentando como um líder, emulando o termo tão importante para os romanos. Aos 44 anos de idade e com duas décadas de produção literária, Horácio está demonstrando que no campo da literatura ele é auctor, ou seja, ele se equipara aos grandes de antes, que são hoje usados como modelo. O valor da produção literária em Roma estava correlacionado com a sua habilidade em reivindicar um elo com o passado da mesma forma que a ancestralidade tinha grande peso dentro da hierarquia social romana (Dolganov, 2008, p. 26).

Augusto também busca na tradição um dos pilares de seu poder, e por isso demonstrou publicamente não ter aceitado nenhum cargo que fosse de encontro ao costume dos ancestrais: "não aceitei nenhuma magistratura outorgada contra o costume dos ancestrais” (Aug. RG 6). A própria auctoritas senatus exemplifica essa tradição romana de que a opinião dos que vieram antes tem grande valor, no costume de os senadores mais velhos terem a primazia na hora dos debates bem como uma grande influência sobre a opinião dos outros membros da casa (Balsdon, 1960, p. 43).

Voltar-se para os modelos, claro, faz parte do próprio modo como a instituição literária é construída na Antiguidade, e nas Epístolas, não só os poetas gregos (Homero, Ênio, Arquíloco, Safo, Alceu) e os filósofos (Aristipo, Epicuro) são elencados no decorrer da obra, mas também o próprio passado poético de Horácio atua como recurso simbólico para o qual o poeta se volta na sua construção como auctor. Embora não esteja ali escrevendo poesia lírica, ele não se afasta completamente desse passado porque aí reside o seu dispositivo de legitimação. Os Carmina aparecem explicitamente na Epístola 1.1, mesmo que seja para programaticamente afastar-se deles; na Epístola 1.13, como presente a ser entregue a Augusto; e nas Epístolas 1.19 e 1.20, como motivo de sua glória. Mas também se manifestam em peças como a Epístola 1.5, na qual o poeta convida Torquato para esquecer os problemas cotidianos e celebrar o aniversário do princeps, fazendo o ambiente simpótico da poesia lírica vir à mente do leitor e, embora Horácio especifique que se trata de um jantar simples (nos versos 1-2 
cita o fato de que, caso aceite o convite, Torquato jantará em pratos e móveis humildes), elementos como o vinho de qualidade e a embriaguez entre amigos remetem à sua lira (v. 4-5; 10-1). A Musa, aliás, é evocada na Epístola 1.8 para levar a carta a Albinovano ("Celso gaudere et bene rem gerere Albinouano/Musa rogata refer [...]", "A Celso Albinovano, alegria e prosperidade,/ ó Musa por mim rogada, leva [...]”, v. 1-2). É outra base para a sua auctoritas: o Horácio do sermo justifica-se pelo Horácio dos carmina, o poeta evoca a sua própria produção como forma de reforçar a legitimidade de sua persona, conferindo peso e credibilidade ao discurso apresentado no decorrer da obra.

Para Horácio, no seu cursus poetarum, os modelos gregos atuam como o seu dispositivo de ancestralidade, de onde advém um amparo para a auctoritas do poeta, que se insere na tradição literária por ter inovado ao emular esses antepassados literários. É como se para Horácio os poetas arcaicos fossem os seus maiores, assim como Eneias e Júlio César o serão para Augusto, que se apropria de ambos para intensificar a sua imagem, utilizando elementos que o ligavam a ambos em moedas, templos e demais veículos discursivos.

\section{CONSIDERAÇÕES FINAIS}

Ser poeta, na Roma do século I a.C., parece ter sido uma posição carregada de ambiguidades, pois ao mesmo tempo que a aristocracia patrocinava poetas e deles se cercava, quase nenhum membro da elite tinha a poesia como ocupação de importância. Para Horácio, justificar por meio da própria poesia o valor desta e de sua carreira parece ter sido de suma importância, como forma de fabricar a ideia de que ser poeta era tão relevante e proporcionaria uma vida tão digna quanto a de alguém que quisesse seguir uma carreira política tradicional. Horácio justifica social e poeticamente sua posição junto à elite, mesmo sendo apenas um homo novus, ao fazer uso transformador do passado, ou seja, revisando o significado de termos essenciais e atualizando dispositivos de valor importantes como conferidores de honra e dignidade dentro da sociedade romana.

\section{REFERÊNCIAS}

ABBOTT, Frank Frost. A History and Description of Roman Political Institutions. London: Atheneum, 1901. 
ATKINS, E. M. Cicero. In: ROWE, Christopher; SCHOFIELD, Malcom (ed.). The Cambridge History of Greek and Roman Political Thought. Cambridge: Cambridge University Press, 2000. p. 477-516.

BADIAN, Ersnt. Nobilitas. In: HAMMOND, Nicholas G. L.; SCULLARD, Howard H. (ed.). The Oxford Classical Dictionary. Oxford: Clarendon, 1970.

BALSDON, John Percy V. D. Auctoritas, dignitas, otium. The Classical Quarterly, v. 10, n. 1, p. 43-50, 1960.

BOURDIEU, Pierre. O poder simbólico. Tradução de Fernando Tomaz. Rio de Janeiro: Bertrand Brasil, 2009.

CICERO. Disputaciones Tusculanas. Traducción de Alberto Medina González. Madrid: Gredos, 2005.

CICERO. Pro Publio Quinctio, Pro Sexto Roscio Amerino, Pro Quincto Roscio Comoedo, De lege agraria I, II, III. Translation by John Henry Freese. Cambridge, MA: Harvard University Press, 1930.

CICERO. De re publica, De legibus. Translation by Clinton Walker Keyes. Cambridge, MA: Harvard University Press, 1977.

COSTA, Lorena L. da. Heróis antigos e modernos: a falsificação para se pensar a História. Belo Horizonte: Fino Traço, 2018.

DABDAB TRABULSI, José Antônio. L'antique et le Contemporain. Paris: Presses Universitaires de Franche-Comte, 2009.

DAVID, Jean-Michel. Rhetoric and Public Life. In: ROSENSTEIN, Nathan; MORSTEIN-MARX, Robert (ed.). A Companion to the Roman Republic. New Jersey: Blackwell, 2006. p. 421-438.

DOLGANOV, Anna. Constructing Author and Authority: Generic Discourse in Cicero's De Legibus. The Classical Association, v. 55, n. 1, p. 23-38, 2008.

DROIT, Roger-Pol (éd.). Les Grecs, les Romains et nous: l'antiquité est-elle moderne? Paris: Le Monde, 1991.

DUQUESNAY, Ian M. Le M. Horace and Maecenas: The Propaganda Value of Sermones I. In: FREUDENBURG, Kirk (ed.). Horace: Satires and Epistles. Oxford: Oxford University Press, 2009. p. 42-101.

ENNIUS. Fragmentary Republican Latin: Testimonia, Epic Fragments. vol. 1. Translation by Sander M. Goldberg e Gesine Manuwald. Cambridge, MA: Harvard University Press, 2018.

FARRELL, Joseph. Greek Lives and Roman Careers in Classical Vita Tradition. In: CHEENEY, Patrick; ARMAS, Frederick A. de. European Literary Careers: The Author from Antiquity to the Renaissance. Toronto: University of Toronto Press, 2002. p. 24-46.

FLOWER, Harriet I. Introduction. In: FLOWER, Harriet I. (ed.). Cambridge Companion to the Roman Republic. Cambridge: Cambridge University Press, 2006. p. 1-14. 
GABBA, Emilio. Republican Rome, the Army and the Allies. Los Angeles: University of California Press, 1976.

GELZER, Matthias. Die Nobilität der römischen Republik. Stuttgart: Teubner, 1912. GOLDSWORTHY, Adrian. The Complete Roman Army. London: Thames \& Hudson, 2007.

GOWERS, Emily. Fragments of Autobiography in Horace Satires I. Classical Antiquity, v. 22, n. 1, p. 55-91, 2003.

GRUEN, Erich S. Augustus and the Making of the Principate. In: GALINSKY, Karl (ed.). The Cambridge Companion to the Age of Augustus. Cambridge: Cambridge University Press, 2007. p. 33-54.

GUTERRES, Tiago da Costa. Heródoto e os poetas: a sphragis e a manifestação autoral nas Histórias. 2012. Dissertação (Mestrado em História) - Programa de Pós-graduação em História, Universidade Federal do Rio Grande do Sul (UFRGS). Porto Alegre, 2012.

HARRISON, Stephen. Deflating the Odes: Horace, Epistles 1.20. The Classical Quarterly, v. 38, n. 2, p. 473-476, 1988.

HARRISON, Stephen. Horatian Self-representations. In: HARRISON, Stephen (ed.). The Cambridge Companion to Horace. Cambridge: Cambridge University Press, 2007. p. 22-35.

HARRISON, Stephen. There and Back Again: Horace's Poetic Career. In: HARDIE, Philip; MOORE, Helen. Classical Literary Careers and Their Reception. Cambridge: Cambridge University Press, 2010. p. 39-58.

HARTOG, François. Os antigos, o passado, o presente. Brasília: Ed. UnB, 2003.

HORÁCIO. Epístolas. In: MACIEL, Bruno Francisco dos S. O poeta ensina a ousar: ironia e didatismo nas Epístolas de Horácio. 2017. Dissertação (Mestrado em Letras) - Programa de Pós-Graduação em Estudos Literários, Universidade Federal de Minas Gerais (UFMG). Belo Horizonte, 2017.

HORÁCIO. Epístolas I. In: PICCOLO, Alexandre P. O Homero de Horácio: intertexto épico no Livro I das Epístolas. 2009. Dissertação (Mestrado em Linguística) - Programa de Pós-graduação em Linguística, Universidade Estadual de Campinas (Unicamp). Campinas, 2009.

HORÁCIO. Odes I. In: FLORES, Guilherme Gontijo. Uma poesia de mosaico nas Odes de Horácio: comentário e tradução poética. 2014. Tese (Doutorado em Letras) Programa de Letras Clássicas, FFLCH, Universidade de São Paulo (USP). São Paulo, 2014.

HORÁCIO. Odes, Epodos e Poema Secular. Tradução de Francisco Antonio Picot. Paris: Librairies-Imprimeries Réunies, 1893.

HORÁCIO. Sátiras. Tradução de Edna Ribeiro Paiva. Niterói: Ed. UFF, 2013. 
KONRAD, Christoph F. From the Gracchi to the First Civil War. In: ROSENSTEIN, Nathan; MORSTEIN-MARX, Robert (ed.). A Companion to the Roman Republic. New Jersey: Blackwell, 2006. p. 167-189.

LONG, George. Libertus. In: SMITH, William (ed.). A dictionary of Greek and Roman Antiquities. London: John Murray, 1875. p. 705-706.

MARTINS, Paulo. Imagem e poder: considerações sobre a representação de Otávio Augusto. São Paulo: Edusp, 2011.

MAYER, Roland. Commentary. In: HORACE. Epistles, Book I. Translation by Roland Mayer. Cambridge: Cambridge University Press, 1994.

MIOTTI, Charlene. Ridentem dicere uerum: o humor retórico de Quintiliano e seu diálogo com Cícero, Catulo e Horácio. 2010. Tese (Doutorado em Letras Clássicas) - Instituto de Estudos da Linguagem, Universidade Estadual de Campinas (Unicamp). Campinas, 2010.

MORLEY, Neville. Social Structure and Demography. In: ROSENSTEIN, Nathan; MORSTEIN-MARX, Robert (ed.). A Companion to the Roman Republic. New Jersey: Blackwell, 2006. p. 299-323.

OLIENSIS, Ellen. Horace and the Rhetoric of Authority. Cambridge: Cambridge University Press, 1998.

OLIENSIS, Ellen. Fashioning Men: The Art of Self-fashioning in the Ars Poetica. In: FREUDENBURG, Kirk (ed.). Horace: Satires and Epistles. Oxford: Oxford University Press, 2009. p. 451-479.

O'NEILL, Jeanne N. Florus and the "Commendatio ad Gloriam" in Horace Epistle 1.13. Phoenix, v. 53, n. 1/2, p. 80-96, 1999.

PATTERSON, John R. Rome and Italy. In: ROSENSTEIN, Nathan; MORSTEIN-MARX, Robert (ed.). A Companion to the Roman Republic. New Jersey: Blackwell, 2006. p. 606-624.

PLUTARCH. The Parallel Lives: Demetrius and Antony, Pyrrhus and Gaius Marius. Translation by Bernadotte Perrin. Cambridge, MA: Harvard University Press, 1920. RAWSON, Elizabeth. Intellectual Life in the Late Roman Republic. London: Duckworth, 1985.

SALÚSTIO; SÊNECA. A conjuração de Catilina; A guerra de Jugurta. In: SALÚSTIO. Tratado sobre a Clemência; A conjuração de Catilina; A guerra de Jugurta. Tradução de Ingeborg Braren e Antônio da Silveira Mendonça. Petrópolis: Vozes, 1990.

SANTANGELO, Federico. Sulla and the Senate: A Reconsideration. Cahiers du Centre Gustave Glotz, n. 17, p. 7-22, 2006.

SHERWIN-WHITE, Adrian Nicholas. Municipium. In: HAMMOND, Nicholas G. L.; SCULLARD, Howard H. (ed.). The Oxford Classical Dictionary. Oxford: Clarendon, 1970.

SILVA, Camilla F. P. da. A representação do lugar social do poeta no Principado de Augusto a partir das Epístolas de Horácio. 2018. Tese (Doutorado em História) 
- Programa de Pós-Graduação em História, Universidade Federal do Espírito Santo (Ufes). Vitória, 2018.

SILVA, Glaydson José. O mundo antigo visto por lentes contemporâneas: as extremas direitas na França nas décadas de 1980 e 90, ou da instrumentalidade da Antigüidade. História, São Paulo, v. 26, n. 1, p. 98-118, 2007.

STEEL, Catherine. The End of the Roman Republic, 146 to 44 BC: Conquest and Crisis. Edinburgh: Edinburgh University Press, 2013.

SYME, Ronald. Augustan Aristocracy. Oxford: Oxford University Press, 1986.

SYME, Ronald. La Revolución Romana. [1939]. Traducción de Antonio Blanco Freijeiro. Crítica: Barcelona, 2011.

TATUM, William J. The final crisis. In: ROSENSTEIN, Nathan; MORSTEIN-MARX, Robert (ed.). A Companion to the Roman Republic. New Jersey: Blackwell, 2006. p. 190-211.

VAN DER BLOM, Henriette. Cicero's Role Models. Oxford: Oxford University Press, 2010.

WIRSZBUSKI, Charles. Libertas as a Political Idea at Rome During the Late Republic and Early Principate. Cambridge: Cambridge University Press, 1950.

WOODMAN, Anthony J. Horace and historians. The Cambridge Classical Journal, v. 55, p. 157-167, 2009.

ZETZEL, James E. G. Poetics of Patronage in the Late First Century B.C. In: GOLD, Barbara K. (ed.). Literary and Artistic Patronage in Ancient Rome. Austin, TX: University of Texas Press, 1982. p. 87-102.

\section{NOTAS}

${ }^{1}$ Cf., entre muitos outros, Droit (1991), Hartog (2003) e, no Brasil, Silva (2007), Dabdab Trabulsi (2009) e Costa (2018).

${ }^{2}$ Tradução nossa. Todas as traduções não referenciadas são de nossa autoria.

${ }^{3}$ Traduções das Odes (Carmina) encontram-se em Horácio (1893) e Horácio (2014).

4 "Non ita Romuli / praescriptum et intonsi Catonis/auspiciis veterumque norma."

${ }^{5}$ Não há uma definição precisa na Antiguidade de novi homini, mas, como demonstra Van der Bloom (2010, p. 35-60), o termo era constantemente utilizado para definir alguns indivíduos, em termos pejorativos ou não, de acordo com a estratégia enunciativa em pauta. Um homo novus seria, em termos gerais, alguém sem um passado familiar glorioso, sem ancestrais que tivessem alguma vez alcançado alguma fama por meio de altos postos políticos, religiosos e/ou militares.

${ }^{6}$ Um municipium, em princípio, representava uma comunidade itálica que possuía determinados direitos sociais romanos, porém sem direito ao voto e à cidadania plena. Funcio- 
nava como uma espécie de aliança. No século I a.C., após a Guerra Civil, a maioria dos municipia itálicos conquistaram o direito ao voto e passaram a ser municipia civium Romanorum (SHERWIN-WHITE, 1970, s.n.p.).

${ }^{7}$ Os equites, a princípio, eram os cavaleiros do exército romano cujos cavalos eram ofertados e cuidados por Roma. Com o passar do tempo passou a ser uma distinção social, a despeito de se ter ou não um cavalo, só podendo ser considerado pertencente à ordem equestre um indivíduo que passasse pelo censo romano, demonstrando ter renda mínima e condições físicas e morais para tal. No final do século II e início do século I a.C., divergiam da ordem senatorial não pela riqueza, mas pelo status (SILVA, 2018, p. 74-75).

${ }^{8}$ A nobilitas pode ser definida como uma elite de um grupo de famílias que mantinham os principais cargos romanos em seu círculo, em especial o consulado. Eram homens de família de prestígio, com todo o aparato magistral e simbólico, possuindo sempre vantagens para se lançar na política por suas redes de sociabilidade. Nunca foi de fato algo fechado, definido por lei, e era constantemente atualizado (BADIAN, 1970, s.n.p.).

${ }^{9}$ Caio Mário, um político de Arpino, era proveniente de uma família sem passado consular ou senatorial (PLUTARCH, 1920, Mar. 3). Sua relação de amicitia com os Cecílios Metelos alçou sua trajetória política, alcançando o Senado. Mário se tornou um bem-sucedido general e empreendeu muitas mudanças nos exércitos, abolindo a necessidade de ser proprietário de terras para ingressar nas legiões, por exemplo. Ele foi rival político de Sula, disputando com este o comando das tropas romanas após o fim das Guerras Sociais.

10 "Nouos nemo tam clarus neque tam egregiis factis erat, quin indignus illo honore et is quasi pollutus haberetur." Salústio (Cat. 23) define da seguinte forma o apoio da aristocracia ao consulado de Cícero simplesmente para contrapor à candidatura de Catilina: "Este fato foi o principal motivo que provocou nas pessoas o desejo de confiar a Cícero o consulado. Realmente a maioria da nobreza até essa data se consumia de inveja e era de parecer que de certa forma se conspurcava o consulado se o conquistasse um homem novo, ainda que de grande valor. Mas com a ameaça do perigo, ficaram para trás a inveja e o orgulho" (SALÚSTIO; SÊNECA, 1990).

${ }^{11}$ Optimates e populares são termos que ficaram associados a grupos de dentro da elite que possuíam apelos, supostamente, diferentes. Como mostrado na argumentação de Cícero, são termos utilizados para o embate político. Os defensores da oligarquia tradicional se declaravam boni ou optimates, e chamavam de populares aqueles membros da elite que estariam, teoricamente, tentando suplantar a autoridade do Senado por meio do apelo às assembleias (KONRAD, 2006, p. 177). Não são, portanto, facções, grupos específicos, tal como se fossem partidos, até porque os chamados populares não consistiam em um movimento contra os senadores, pois eles mesmos eram aristocratas e senadores (TATUM, 2006, p. 191).

${ }^{12}$ Um libertus era um indivíduo que havia sido anteriormente escravo e, após a manumissão, se tornara parte dos libertini (LONG, 1875, p. 705).

${ }^{13}$ Dignitas era um termo com ampla significação, por vezes traduzido por dignidade, mas que pode ser entendido como o nome conceituado de alguém, sua reputação; Júlio César, ao 
ser convocado pelo Senado para ir a Roma, sem nenhum ofício, para ser julgado por crimes de guerra, proclamou que sua dignitas havia sido ofendida (BALSDON, 1960, p. 45).

${ }^{14}$ Catulo, como Farrell (2002, p. 43) demonstra, é o único dos neotéricos a desdenhar a carreira pública: os homens das letras de seu tempo - Calvo, Cinna, Asínio Polião e Cornélio Galo -, todos empenharam-se no cursus honorum.

${ }^{15}$ A hera era considerada a coroa das Musas e também de Baco, associada, assim, à poesia e aos poetas.

16 Traduções em Horácio (2014).

17 "hoc ego commodius quam tu, praeclare senator,/ milibus atque aliis vivo. quacumque libido est,/ incedo solus, percontor quanti holus ac far,/ fallacem circum vespertinumque pererro/ saepe forum, [...]/ deinde eo dormitum, non sollicitus, mihi quod cras/surgendum sit mane [...]/ ad quartam iaceo; post hanc vagor aut ego lecto/ aut scripto quod me tacitum iuvet unguor olivo, [...] ast ubi me fessum sol acrior ire lavatum/ admonuit, fugio campum lusumque trigonem."

${ }^{18} \mathrm{O}$ tribunato militar era um posto do exército romano e, a princípio, os homens escolhidos para ocupá-lo pertenciam à aristocracia tradicional. No século I a.C., esse posto foi cada vez mais sendo vinculado à ordem equestre (cf. GOLDSWORTHY, 2007).

19 "[...] meis contentus honestos/fascibus et sellis nollem mihi sumere, demens/ iudicio volgi, sanus fortasse tuo, quod/ nollem onus haud umquam solitus portare molestum" (HORÁCIO, 2013).

${ }^{20}$ DuQuesnay (2009, p. 92), tomando como base passagens de Veleio Patérculo e Sêneca, o filósofo, afirma que sua opção por preferir a vida de otium pode ter sido vista pelos contemporâneos como algo no mínimo curioso.

21 "haec est/vita solutorum misera ambitione gravique; his me consolor victurum suavius ac sil quaestor avus pater atque meus patruusque fuisset."

${ }^{22}$ Conforme Wirszbuski (1950, p. 3-4), a libertas era um conceito que tinha caráter cívico, indissociável de civitas, algo que definia a posição dos indivíduos que possuíssem todos os direitos, pessoais e políticos.

${ }^{23}$ Vates era um vocábulo arcaico latino ligado ao âmbito divino, à profecia, que foi recuperado pelos poetas do final do século I a.C. para se referirem a eles mesmos (SILVA, 2018, p. 221).

${ }^{24}$ Sphragis é "o elemento que remete ao sujeito produtor da obra", é uma marca que o enunciador deixa sobre si no texto (GUTERRES, 2012, p. 5). Ela é, de certa forma, um elemento de cunho autobiográfico, fictício ou não.

${ }^{25}$ A auctoritas pode ser entendida como o prestígio de um indivíduo perante a sociedade romana, que é depreendido de seus sucessos militares, políticos e afins.

26 "[...] Ipse quid audes?/ quae circumuolitas agilis thyma? non tibi paruom/ ingenium, non incultum est et turpiter hirtum;/ seu linguam causis acuis seu ciuica iura/ respondere paras seu condis amabile carmen,/ prima feres hederae uictricis praemia" (HORÁCIO, 2009). 
27 "Libera per uacuum posui uestigia princeps,/ non aliena meo pressi pede. Qui sibi fidet,/ dux reget examen. Parios ego primus iambos/ostendi Latio, [...] ac ne me foliis ideo breuioribus ornes/ quod timui mutare modos et carminis artem, [...]/ Hunc ego, non alio dictum prius ore, Latinus/ uolgaui fidicen; iunat inmemorata ferentem/ingenuis oculisque legi manibusque teneri" (HORÁCIO, 2017).

${ }^{28} \mathrm{Na}$ Epístola 1.17, v. 35, por exemplo, o poeta expressa que agradar aos primeiros de Roma era uma tarefa honrosa, tópico que vai aparecer em diversos outros lugares das obras horacianas. Na sphragis da Epistola 1.20, orgulha-se o poeta: "me primis urbis belli placuisse domique", "os primeiros em Roma me favoreceram, na guerra e na paz" (HORÁCIO, 2009). 